\title{
A prospective study comparing injectable interferon beta-1a (Rebif 22-44), (Avonex 30) and 1b (Betaseron 250) injection site reaction in multiple sclerosis patients
}

\author{
Foziah Jabbar Alshamrani ${ }^{1}$, Hind Alnajashi ${ }^{2}$, Fahad Alkhamis ${ }^{3}$, Ibrahim Alghanimi ${ }^{1}$, Abdulla Alsulaiman ${ }^{1}$, \\ Aishah Albaker ${ }^{1}$, Iqbal bukari ${ }^{4}$, Amir Mohamad ${ }^{5}$
}

${ }^{1}$ MD, Assistant Professor, Imam Abdurrahman bin Faisal University-King Fahd University Hospital, Dammam, Saudi Arabia

${ }^{2}$ MD, Assistant Professor, College of Medicine, King Abdulaziz University, Jeddah, Saudi Arabia

${ }^{3}$ MD, Associate Professor, Imam Abdurrahman bin Faisal University-King Fahd University Hospital, Dammam, Saudi Arabia

${ }^{4}$ MD, Professor, Imam Abdurrahman bin Faisal University-King Fahd University Hospital, Dammam, Saudi Arabia

${ }^{5}$ Assistant Professor, Imam Abdurrahman bin Faisal University-King Fahd University Hospital, Dammam, Saudi Arabia

\section{Type of article: Original}

\begin{abstract}
Background: Multiple sclerosis (MS) is one of the neuroinflammatory disorders that commonly affect the young. Injectable interferons beta-1a (Rebif 22-44, Betaseron 250 and Avonex 30) are one of the most important first line disease modifying therapies with less side effects compared to others. But the injection site reaction (ISR) is an important side effect, which can decrease the patient's compliance to the medications that will lead to the disease progression.

Objective: The purpose of this study was to compare the ISR in the three types of interferon (2 subcutaneous Rebif 22-44, Betaseron 250 and one intramuscular Avonex 30) and determine whether the route of administration (subcutaneous versus intramuscular) affects the frequency of ISR, and to reduce this side effect and ensure compliance.

Methods: This was a single center, prospective observational study of 300 patients at King Fahad University Hospital (Al Khobar, Saudi Arabia) form September 2015 to August 2016 with a relapsing remitting form of multiple sclerosis for which 114 patents were receiving injectable interferon. A questionnaire was filled out by the participants including type of interferon, type of ISR and pain severity. Patients were then evaluated in our MS clinic and dermatology clinic after 1 week and 3 months. Data were analyzed by IBM-SPSS version 21. Appropriate statistical tests will be mandated per the collected data. Statistical significance is determined at pvalue $<0.05$ with a confidence interval of 0.95 . Frequency and proportion, and relative risks (RR) were calculated and Chi-square test was used.

Results: ISRs in the form of erythema were reported by fewer patients on Avonex group $21.1 \%$ compared to the other two injectables, Betaseron group (77.8\%, $\mathrm{p}<0.0001, \mathrm{RR}=2.6)$ and Rebif groups $(69.8 \%, \mathrm{p}<0.0001$, $\mathrm{RR}=2.3$ ). Similar observations were noticed 3 months later, where the Avonex group had statistically significant less ISRs with no abnormality in $89.9 \%$ compared to $(52.3 \%, \mathrm{p}<0.0001, \mathrm{RR}=3.5)$ and $(44.4 \%, \mathrm{p}<0.0001$, $\mathrm{RR}=4.2)$ in Rebif and Betaseron respectively. Only patients on Rebif had skin ulceration $3.5 \%(\mathrm{n}=3)$ at initial assessment; however, there was insignificant difference and none of the patients had skin ulceration at the 3 months' evaluation.
\end{abstract}

Conclusions: Interferon beta-1a (Avonex) found to be the least to cause ISR compared to Rebif and Betaseron. Keywords: Multiple sclerosis, Injection site reaction (ISR), Interferon beta

\section{Corresponding author:}

Assistant Professor Dr. Foziah Jabbar Alshamrani, P.O. Box 40114, Al Khobar 3195, Saudi Arabia.

Tel: +966501865577 and 0096613896666,Email: fshamrani@iau.edu.sa and Fo0og@hotmail.com

Received: December 12, 2018, Accepted: February 20, 2019, Published: September 2019

iThenticate screening: February 19, 2019, English editing: March 16, 2019, Quality control: July 18, 2019

This article has been reviewed / commented by three experts

Ethics approval: ethical review board of the Imam Abdurrahman Bin Faisal University (Ref: IRB-2014-01307).

(C) 2019 The Authors. This is an open access article under the terms of the Creative Commons Attribution-NonCommercialNoDerivs License, which permits use and distribution in any medium, provided the original work is properly cited, the use is non-commercial and no modifications or adaptations are made. 


\title{
Abbreviations / Acronyms:
}

ALT: Alanine Aminotransferase; IM: Intramuscular; INF: Interferon; IFNB-1a: Interferon beta 1a; IFNB-1b: Interferon beta 1b; ISP: Injection Site Pain; ISR: Injection Site Reaction; MS: Multiple Sclerosis; RR: Relative Risk; SC: Subcutaneous; ULN: Upper Limit of Normal; VAS: Visual Analogue Scale

\begin{abstract}
1. Introduction
Injection site reaction (ISR) and pain occur frequently on patients receiving interferon injections $(1,2)$ with unclear cause. Reaction ranges from mild erythema to rare occurrence of skin necrosis, which can cause discomfort to the patient and subsequent discontinuation of the treatment (3). Instructions should be given to the patients to minimize those reactions, such as correct use of injectors $(4,5)$ site massage, hot or cold compression and avoiding sun exposure to the injection site. Comparing the injection site reaction on patients using interferons was mentioned in earlier literature, such as a previous BRIGHT study between interferon beta-1b (Betaseron) 250 mg subcutaneously every other day and interferon beta-1a (Rebif) 44mg subcutaneously three times weekly in patients with relapsingremitting MS. The study showed that the proportion of pain-free patients was higher with Betaferon than with Rebif, and the ISRs occurred in a significantly lower proportion of patients with Betaseron than with Rebif (6). The Canadian Betaseron versus Rebif study on injection site pain shows the same findings of the previous two studies that indicate that subcutaneous injection with interferon beta-1b is associated with a lower incidence and severity of pain than subcutaneous injection with interferon beta-1a in patients with MS (7). There are some data from a small comparative study comparing Betaseron and Rebif injection, suggesting that the occurrence and severity of injection site pain (ISP) may vary with the high-frequency therapy received (7). The aim of this study was to compare the three types of injectable INF, ISR and ISP in our patients at King Fahad University Hospital as the previous studies compared the subcutaneous type of INF only, and to determine whether the route of administration effects ISR frequency; to facilitate the choice between those injectable INFs in patients who had side effects with ISR. The most common side effect for INFs is ISR, so, minimizing those ISRs can lead to more treatment adherence.
\end{abstract}

\section{Material and Methods}

\subsection{Research design and participants}

This was an observational study at a single center (King Fahad University Hospital) at Al Khobar, Saudi Arabia. A total of 114 multiple sclerosis patients were selected to participate in this study form September 2014 to August 2015 to compare (2 subcutaneous Rebif 22-44, Betaseron 250 and one intramuscular Avonex 30) and determine whether the route of administration effects frequency of ISR.

\subsection{Sample size and sampling method}

A total of 114 subjects with MS $n=42(36.8 \%)$ male and $n=72(63.2 \%)$ female were included in this study. Sample size was calculated as follows: 1) Rebif $[n=86(75.4 \%)], 2)$ Betaseron $[n=9(7.9 \%)]$, and 3) Avonex [n=19 (16.7\%)].

\subsection{Inclusion criteria}

The following were set as the inclusion criteria:

1) Patients aged between 18 to 54 years of both genders

2) Patients with a definite diagnosis of relapsing remitting multiple sclerosis (RRMS)

3) Justified prescription of one interferon beta by subcutaneous or intramuscular routes as following Interferon beta $1 \mathrm{~b}$ ([IFNB-1b] Betaferon $250 \mathrm{mcg}(8 \mathrm{mIU})$ administered on intermittent days by subcutaneous injection using Betaject Lite Interferon beta-1a ([IFNB-1a] Rebif) $22 \mathrm{mcg}-44 \mathrm{mcg}(6-12 \mathrm{mIU})$ three times per week by subcutaneous injection using Rebiject II or Interferon beta-1a (IFNB-1a) Avonex $30 \mathrm{mg}$ intramuscular weekly either for the first time or previously prescribed.

\subsection{Exclusion Criteria}

The exclusion criteria were:

1) Any contraindication to the prescription of interferon beta 1b SC (Betaferon), interferon beta 1a SC (Rebif) or interferon beta 1a IM (Avonex)

2) Pregnancy or lactation

3) Known hypersensitivity to natural or recombinant interferon beta, to mannitol, to human albumin or any other excipients used

4) History of severe depression or suicide attempt or current suicidal ideation 
5) Inadequate liver function, defined by a alanine aminotransferase (ALT) $>3 \mathrm{x}$ upper limit of normal (ULN), or alkaline phosphatase $>2 \times$ ULN, or total bilirubin $>2 \times$ ULN if associated with any elevation of ALT or alkaline phosphatase

6) Inadequate bone marrow reserve, defined as a white blood cell count less than $0.5 \mathrm{x}$ lower limit of normal

7) Epilepsy not adequately controlled by treatment

8) Medical, psychiatric or other conditions that compromise the patient's ability to understand the patient information, to give informed consent, to comply with the trial protocol or to complete the study

9) History of any chronic pain syndrome and any visual or physical impairment that precludes the subject from self-injecting the treatment using the injection.

\subsection{Instrument and data collection}

Assessment is carried out by clinical examination at 1 week after interferon injections and followed up at 3 months for the same site in neurology and dermatology clinic. Percentage of site reaction 24 Hours after injection as reported by participants, then 1 week by the physician up to 3 months, Scoring system of site reaction based on previous trial (Bayer Study Director Bayer, August 2013), Score range is: 0 (no abnormal reaction), 1 (erythema), 2 (edema), 3 (infiltration), 4 (ulceration or necrosis). Mean Pain Assessment using Visual Analogue Scale (VAS) as reported by participants 24 hours after injection scale was used to report the pain from 0 (no pain) to 10 (maximal pain).

\subsection{Statistical methods}

Data were analyzed by IBM $\odot$ SPSS $\odot$ Statistics version 21 (IBM@ Corp., Armonk, NY, USA). Relative Risk (RR), Chi-square, and statistical significance were calculated and analyzed. Statistical significance is determined at $\mathrm{p}$ value $<0.05$ with a confidence interval of 0.95 .

\subsection{Ethics of research}

This study was approved by the local Human Research Ethics Committee. The ethical review board of the Imam Abdurrahman Bin Faisal University approved the project (Ref: IRB-2014-01307). All participants received a complete description of the study and granted written informed consent. Each patient received sufficient education regarding injection and appropriate injector use. Females of child-bearing potential agreed to practice adequate contraceptive methods over the duration of the study (not applicable for men).

\section{Results}

Of a total of 114 patients diagnosed with MS (42 male, 36.8\% and 72 female, 63.2\%),the overall mean age at enrollment was 33.5 years $( \pm 9.3)$ and age range was 18 to 54 years. Participants on this study were either on Rebif $(\mathrm{n}=86,75.4 \%)$, Betaseron $(\mathrm{n}=9,7.9 \%)$, or Avonex $(\mathrm{n}=19,16.7 \%)$. At first evaluation, ISRs in the form of erythema were reported by fewer patients in the Avonex group ( $\mathrm{n}=4,21.1 \%)$ than the Betaseron group $(\mathrm{n}=7,77.8 \%)$ and Rebif group $(\mathrm{n}=60,69.8 \%)(\mathrm{p}<0.0001)$ (Figure 1). ISRs were less in the Avonex group compared to the Betaseron group $(\mathrm{RR}=2.6)$ and Rebif group $(\mathrm{R} R=2.3)$. Similar observations were noticed 3 months later, where the Avonex group had statistically significant less ISRs with no abnormality in $89.9 \%(\mathrm{n}=17)$ compared to $52.3 \%(\mathrm{n}=45, \mathrm{p}<0.0001$, $\mathrm{RR}=3.5)$ and $44.4 \%(\mathrm{n}=4, \mathrm{p}<0.0001, \mathrm{RR}=4.2)$ in Rebif and Betaseron groups respectively. Only patients on the Rebif group had skin ulceration 3.5\% $(\mathrm{n}=3)$ at initial assessment, however, the difference was insignificant and none of the patients had skin ulceration at 3 months' evaluation (Table 1).

Table 1. Injection site reaction at three month assessment

\begin{tabular}{|l|l|l|l|}
\hline \multirow{2}{*}{ ISR } & \multicolumn{3}{|l|}{ Type of INF; n (\%) } \\
\cline { 2 - 4 } & Rebif & Betaseron & Avonex \\
\hline No abnormality & $45(52.3)$ & $4(44.4)$ & $17(89.5)$ \\
\hline Erythema & $41(47.7)$ & $4(44.4)$ & $2(10.5)$ \\
\hline Eodema & $0(0.0)$ & $0(0.0)$ & $0(0.0)$ \\
\hline Infiltration & $0(0.0)$ & $1(11.1)$ & $0(0.0)$ \\
\hline Ulceration & $0(0.0)$ & $0(0.0)$ & $0(0.0)$ \\
\hline p-value: 0.000 \\
\hline
\end{tabular}

ISR: Injection site reaction 


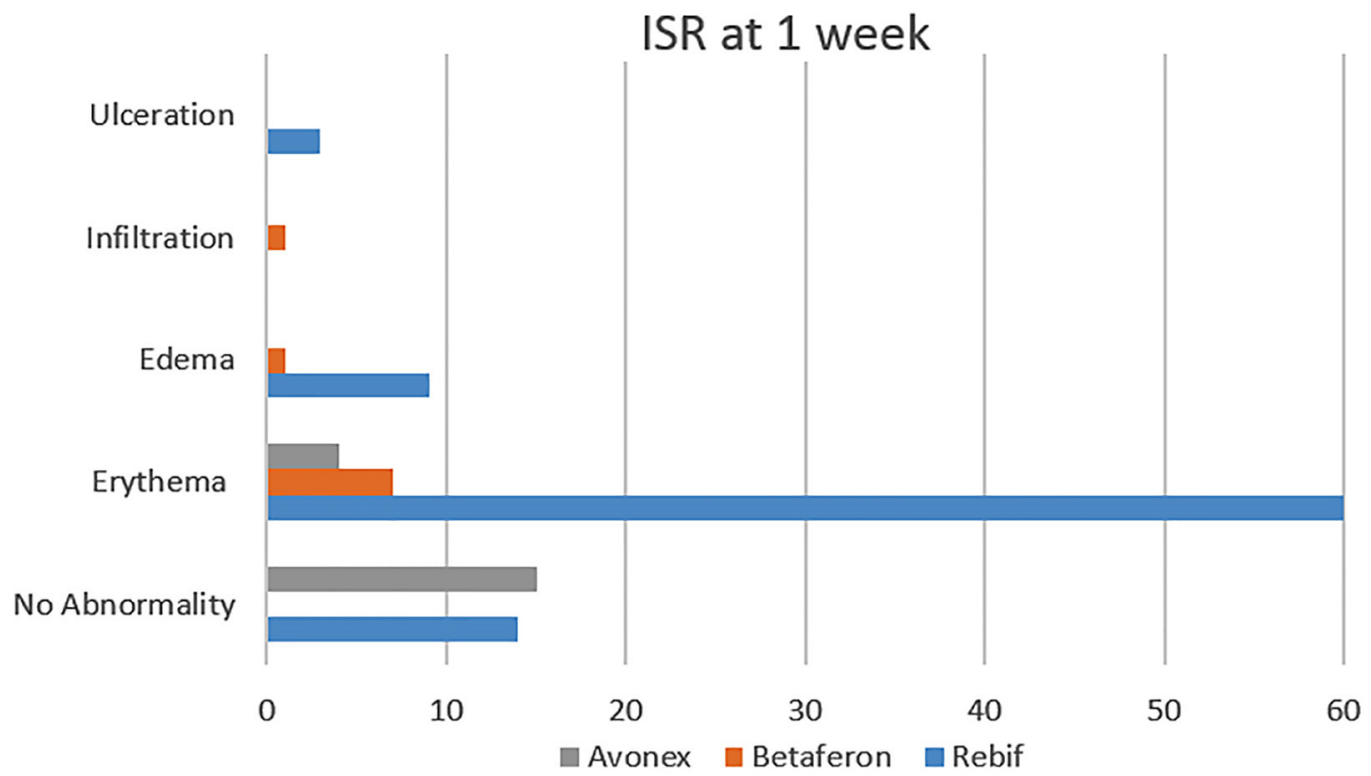

Figure 1. Frequency of Injection Site Reaction at the Initial Assessment

Regarding the injection site pain (ISP) score, no statistically significant differences were found between the three groups. In the Rebif group, $61.6 \%$ of patients experienced no pain or mild annoying pain, $44.4 \%$ in the Betaferon group experienced no pain or mild annoying pain, and $42.1 \%$ in the Avonex group showed the same. In the Rebif group, $1.2 \%$ patients and in the Avonex group, $5.3 \%$ patients showed intense unbearable pain. Therefore, Avonex was the least to cause injection site reaction compared to Rebif and Betaseron. However, no significant differences were found between the three injectable disease modifying therapies in regard to pain (Table 2).

Table 2. Pain severity in the three groups at initial assessment.

\begin{tabular}{|l|l|l|l|}
\hline \multirow{2}{*}{ Pain severity } & \multicolumn{3}{|l|}{ Type of INF; n (\%) } \\
\cline { 2 - 4 } & Rebif & Betaseron & Avonex \\
\hline No pain and mild annoying pain & $53(61.6)$ & $4(44.4)$ & $8(42.1)$ \\
\hline Nagging uncomfortable troublesome pain & $32(37.2)$ & $5(55.6)$ & $10(52.6)$ \\
\hline Intense dreadful horrible pain & $1(1.2)$ & $0(0.0)$ & $1(5.3)$ \\
\hline p-value: 0.360 & \multicolumn{3}{l}{} \\
\hline
\end{tabular}

\section{Discussion}

ISRs are a common side effect of injectable DMTs. This is the first study comparing the frequency and severity of ISP and ISR among the three types of injectable interferon. In our study, by adding Avonex, which had different routes of administration as being intramuscular to the comparison, we found it the least in causing ISR. These reactions can happen secondary to chemical aspects of agents components or mechanical issues as well as whether using injectors or not, and the needle gauge size. Comparing injectable interferon efficacy and tolerability were studied in multiple trails (8-10) which are compatible with our study that show they are all effective and tolerable with few sides effects, as well as comparing the ISP and ISR between two of them as Betaseron and Rebif (1) that states that the Betaferon is lower to cause ISR and ISP, although, both of them were used by injector, which can decrease the ISR to some extent, but this could be related to the acidity PH component of them.

All previous studies support Betaseron being the least to cause ISR and ISP, but adding the Avonex to the comparison in our study changed the scale, making it the best recommendation to any patient who had any issues with treatment site reaction. This advantage of being least to cause ISP is added to its dosing frequency being used once per week. Cutaneous adverse events associated with interferon- $\beta$ treatment of Multiple Sclerosis as well as new-onset and exacerbation of psoriasis has also described (11). ISR is an issue that can cause discontinuation of the treatment because of cosmetic concerns as well as depressive symptoms $(12,13)$, therefore, we need to minimize these complications that can be caused by the treatment, and increase the patients' satisfaction. Some techniques can be somewhat helpful -to limit unwanted ISR, such as use of an auto injector, cooling pack, massage and site rotation. 


\section{Strengths and limitations}

To our knowledge, this is the first study that compares the three injectable interferon ISRs. This was an observational study and future studies with more patients in the Betaseron group are recommended. Another two limitations that were found during the data collection were that some patients are not continuously using the injectors, so we cannot label them as fixed users of injectors or not. The other limitation is forgetting to record the exact site examined for the ISR to follow it up in the next three months, which leads to repeating the exam for the patient for a new site and the needle gauge size, which was not studied here (14-16) and probably will need further studies assessing the injectors, needle depth and gauge as contributing factors for the ISR and ISP. This study was done with the approval of RebiSmart modern injectors for Rebif.

\section{Conclusions}

The most common side effect for patients taking injectable INFs is ISR and this side effect decreases the treatment adherence. Our study found that Avonex is the lowest causing ISR. This will lead to more adherences for medication and avoid noncompliance. Further future studies are needed with a larger number of patients to clarify the cause of these side effects and study different methods of injection for less ISR

\section{Acknowledgments:}

Sincere appreciation is conveyed to the Department of Statistics, at King Fahd University Hospital in Saudi Arabia for the help in statistics. This study was conducted without any specific funding resources.

\section{Conflict of Interest:}

There is no conflict of interest to be declared.

\section{Authors' contributions:}

All authors contributed to conception or design of the work, Acquisition of data, and Analysis or interpretation of data equally. All authors contributed to drafting and revising the manuscript equally. All authors read and approved the final manuscript.

\section{References:}

1) The Interferon Beta Multiple Sclerosis Study Group and the University of British Columbia MS/MRI Analysis Group. Interferon beta- $1 \mathrm{~b}$ in the treatment of multiple sclerosis: final outcome of the ran-domized controlled trial. Neurology. 1995; 45: 1277-85. doi: 10.1212/WNL.45.7.1277.

2) Bayas A, Rieckmann P. Managing the adverse effects of interferon-beta therapy in multiple sclerosis. Drug Saf. 2000; 22: 149-59. doi: 10.2165/00002018-200022020-00006. PMID: 10672896.

3) Elgart GW, Sheremata W, Ahn YS. Cutaneous reac-tions to recombinant human interferon beta-1b: the clinical and histologic spectrum. J Am Acad Dermatol. 1997; 37: 553-58. doi: 10.1016/S01909622(97)70170-1.

4) Tornatore $\mathrm{C}$, Bartlett $\mathrm{D}$. Tolerability of interferon beta-1b (Betaferon ${ }^{\mathrm{TM}} /$ Betaseron $^{\mathrm{TM}}$ ) can be significantly improved using both interferon-free needle and auto-mated injection techniques. J Neurol. 2002; 249(Suppl 1): 205

5) Brochet B, Lemaire G, Beddiaf A. Reduction of injection site reactions in multiple sclerosis patients newly started on interferon beta $1 \mathrm{~b}$ therapy with two different devices. Rev Neurol. 2006; 162: 735-40. doi: 10.1016/S0035-3787(06)75071-8.

6) Baum K, O'leary C, Ferrer FC, Klimova E, Prochazkova L, Bugge J. Comparison of injection site pain and injection site reactions in relapsing-remitting multiple sclerosis patients treated with interferon beta-1a or 1b. Mult Scler. 2007; 13(9): 1153-60. doi: 10.1177/1352458507079291. PMID: 17967843.

7) Harris C, Billisberger K, Tillotson L, Peters S, Pederson C, Becker M. Injection site pain in patients with multiple sclerosis: interferon beta-1b ver-sus interferon beta-1a. Int J MS Care. 2005/2006; 7(4): 132-6. doi: 10.7224/1537-2073-7.4.132.

8) Panitch H, Goodin DS, Francis G, Chang P, Coyle PK, O'Connor P, et al. Randomized, comparative study of interferon beta-1a treatment regimens in MS: the EVIDENCE Trial. Neurology. 2002; 59: 1496-506. doi: 10.1212/01.wnl.0000034080.43681.da. PMID: 12451188.

9) Kappos L, Polman CH, Freedman MS, Edan G, Hartung HP, Miller DH, et al. Treatment with interferon beta-1b delays con-version to clinically definite and McDonald MS in patients with clinically isolated syndromes. Neurology. 2006; 67(7): 1242-9. doi: 10.1212/01.wnl.0000237641.33768.8d. PMID: 16914693. 
10) Goodin DS, Frohman EM, Garmany Jr GP, Halper J, Likosky WH, Lublin FD, et al. Disease modifying therapies in mul-tiple sclerosis: report of the Therapeutics and Technology Assessment Subcommittee of the American Academy of Neurology and the MS Council for Clinical Practice Guidelines. Neurology. 2002; 58: 169-78. doi: 10.1212/WNL.58.2.169. PMID: 11805241.

11) Kolb-Mäurer A, Goebeler M, Mäurer M. Cutaneous Adverse Events Associated with Interferon- $\beta$ Treatment of Multiple Sclerosis. Int J Mol Sci. 2015; 16(7): 14951-60. doi: 10.3390/ijms160714951. PMID: 26147425. PMCID: PMC4519881.

12) Archibald CJ, McGrath PJ, Ritvo PG, Fisk JD, Bhan V, Maxner CE, et al. Pain prevalence, severity and impact in a clinic sample of multiple sclerosis patients. Pain. 1994; 58: 89-93 doi: 10.1016/03043959(94)90188-0.

13) Kassirer M. Multiple sclerosis and pain: a medical focus. Int J MS Care. 2000; 2: 30-4. doi: 10.7224/15372073-2.3.40.

14) Lesaux J, Jadback G, Harraghy CE. Improving the convenience of home-based interferon beta-1atherapy for multiple sclerosis. J Neurosci Nurs. 1999; 31: 174-79. doi: 10.1097/01376517-199906000-00006. PMID: 10846648.

15) Mikol D, Lopez-Bresnahan M, Taraskiewicz S, Chang P, Rangnow J. A randomized, multicentre, openlabel, parallel-group trial of the tolerability of interferon beta-1a (Rebif) adminis-tered by autoinjection or manual injection in relapsing-remitting multiple sclerosis. Mult Scler. 2005; 11: 585-91. doi: 10.1191/1352458505ms1197oa. PMID: 16193898.

16) Balak DM, Hengstman GJ, Çakmak A, Thio HB. Cutaneous adverse events associated with diseasemodifying treatment in multiple sclerosis: A systematic review. Mult Scler. 2012; 18: 1705-17. doi: 10.1177/1352458512438239. PMID: 22371220. 